\title{
ANÁLISE TEMPORAL DO USO E DA COBERTURA DO SOLO NAS ÁREAS DESFLORESTADAS DO MUNICÍPIO DE ALTAMIRA, PARÁ
}

Essía de Paula Romão ${ }^{1}$, Altem Nascimento Pontes ${ }^{2}$, Ana Lúcia Nunes Gutjahr ${ }^{3}$, Walber Roberto Guimarães Torres ${ }^{4}$

1 Professora Mestre do Instituto Federal de Educação, Ciência e Tecnologia do Pará. (essiageo@hotmail.com) Belém-Brasil.

2 Professor Doutor da Universidade do Estado do Pará.

3 Professora Doutora da Universidade do Estado do Pará.

4 Colaborador do Instituto Nacional de Pesquisas Espaciais (INPE/CRA).

Recebido em: 08/04/2017 - Aprovado em: 10/06/2017 - Publicado em: 20/06/2017

DOI: 10.18677/EnciBio_2017A11

\begin{abstract}
RESUMO
O município de Altamira destaca-se por altos índices de desmatamento que transformam áreas naturais em outras formas de uso, provocando perda de biodiversidade e redução de serviços ambientais. $O$ presente artigo analisa as mudanças no uso e cobertura do solo nas áreas desflorestadas do município de Altamira-PA nos anos de 2008 e 2012. Foram utilizados os dados do TerraClass, tratados nos softwares Spring para união e análise dos raster e o TerraAmazon para o design dos mapas. Constatou-se que houve um aumento nas formas de uso: Área Urbana, Mineração, Pasto Limpo, Pasto Sujo e Regeneração com Pasto. A classe Floresta obteve uma redução de sua cobertura, enquanto Vegetação Secundária apresentou aumento. Houve uma dinâmica no uso e cobertura do solo, onde diferentes formas de usos expandiram e reduziram suas áreas. Assim, faz-se necessário ampliar a escala temporal desta análise, reduzir a supressão da floresta nativa e manter fisionomias em regeneração.
\end{abstract}

PALAVRAS-CHAVE: Altamira, Desmatamento. TerraClass.

\section{ANALYZE TEMPORAL OF THE USE AND OF THE COVERING OF THE SOIL IN THE DEFORESTED AREAS OF THE MUNICIPAL DISTRICT OF ALTAMIRA, PARÁ}

\footnotetext{
ABSTRACT

The city of Altamira is notable for high rates of deforestation that transform natural areas in other forms of use, causing loss of biodiversity and reduction of environmental services. This article analyzes the changes in land use and land cover in deforested areas in the municipality of Altamira-PA in 2008 and 2012. TerraClass the data were used, treated in Spring software for union and analysis of raster and TerraAmazon for design maps. It was found that there was an increase in the forms of use: Urban Area, Mining, Clean Pasto, Pasto grimy and regeneration with pasture. The Forest class obtained a reduction of coverage, while Secondary Vegetation showed an increase. There was a dynamic use and soil cover, where different forms of uses expanded and reduced their areas. Thus, it is necessary to extend the time ENCICLOPÉDIA BIOSFERA, Centro Científico Conhecer - Goiânia, v.14 n.25; p.113 2017
} 
scale of this analysis, reduce the suppression of native forest and keep faces in regeneration.

KEYWORDS: Deforestation. TerraClass. Altamira.

\section{INTRODUÇÃO}

O acelerado crescimento demográfico em função da satisfação humana gera diversas demandas por recursos naturais, causando modificações ambientais que alteram a paisagem (MORAIS \& CARVALHO, 2013), desencadeando consequências irreparáveis aos serviços ambientais (VIEIRA et al., 2005), perda de biodiversidade, alterações nos ciclos bioquímicos e modificação do balanço energético dos ecossistemas (LAURANCE, 2008). Nesta ótica, tais alterações podem ser analisadas em escala local e regional, por meio da interação de energias que ocorrem entre a superfície e a atmosfera terrestre (FOLEY et al., 2005).

Assim, as mudanças no uso da terra e os altos índices de desmatamento vêm modificando o cenário natural das florestas. Admite-se que $32 \%$ do desmatamento são provenientes de florestas tropicais sul-americanas (HANSEN, 2013; MEIRELLES FILHO, 2014). Nesta realidade, destaca-se a 'Amazônia Legal' por apresentar uma alta redução da cobertura original, proveniente de ciclos econômicos introduzidos no processo histórico de ocupação da região (FEARNSIDE, 2005). Contudo, a floresta amazônica brasileira encontra-se sob um cenário de grande pressão demográfica, desencadeado por projetos de ocupação que deram origem a diversas cidades (BECKER, 1995), fomentando o desmatamento e afetando diretamente sua biodiversidade. Assim, em um período médio de cinco décadas, a floresta amazônica foi reduzida $18 \%$ em decorrência do desmatamento, uma taxa com proporção de aproximadamente $14 \%$ de supressão de sua área total (IBGE, 2011, INPE, 2011).

Dessa forma, o processo de ocupação humano na Amazônia foi fomentado pela expansão agropecuária, investimentos em infraestrutura, com abertura e pavimentação de estradas, de atividades mineradoras e projetos hidroelétricos, através de incentivos fiscais e políticas de colonização, que provocaram um forte movimento migratório para a região, desencadeando o estímulo ao desmatamento e, consequentemente, a alteração da paisagem, com grandes impactos na dinâmica biológica (IANNI, 1979; MAHAR, 1989; BECKER, 1998; FEARNSIDE, 2005; CASTRO, 2007; COUTINHO, 2009; ALMEIDA et al., 2010; MEIRELLES FILHO, 2014; FEARNSIDE, 2015;).

Neste contexto, se enquadra o estado do Pará, onde a amplitude dos rios e a abertura de estradas, favoreceu o surgimento de muitas cidades, como o município de Altamira, que teve seu processo de povoamento e ocupação iniciado às margens do rio Xingu, em meados do século XVII (CARDOSO \& NEGRÃO, 2012; UMBUZEIRO, 2012). Na década de 1970, Altamira sofre um alto impulso populacional e migratório com a construção da rodovia Transamazônica (BR 230) e, na atualidade, a hidrelétrica de Belo Monte tem alterado a demografia local com um acréscimo populacional em torno de 25 a 40 mil habitantes, mediante a oportunidades e estímulos promovidos pelo grande porte deste projeto, provocando fortes transformações na paisagem (HERRERA \& MOREIRA, 2013; CORDOVIL et al., 2014; GIRALDIN, 2015).

Portanto, em meados dos anos 80 , foi iniciado no Instituto Nacional de Pesquisas Espaciais, o PRODES (Programa de Monitoramento do Desflorestamento das Formações Vegetais da Amazônia Legal) para monitorar o processo de supressão da floresta na região Amazônica. Esta ferramenta surge para quantificar 
os níveis de desflorestamento na Amazônia Brasileira. Entretanto, com a massificação do acesso à região, novos atores foram incorporados à dinâmica econômica amazônica, tornando-a mais complexa, demandando novos questionamentos e análises. Neste contexto, surgiu o Projeto TerraClass, que procurou incorporar uma nova visão a respeito da complexidade que envolvia o desmatamento na Amazônia, analisando e classificando os diferentes usos e ocupação das áreas desmatadas e já monitoradas pelo PRODES (INPE \& EMBRAPA, 2013).

Pelo exposto, o presente estudo visou analisar o uso e a cobertura do solo nas áreas desflorestadas do município de Altamira-PA, por meio de técnicas do Sistema de Informações Geográficas (SIG), fazendo uso dos dados do Programa TerraClass, mapeados e publicadas pelo Projeto PRODES.

\section{MATERIAL E MÉTODOS}

\section{Área de estudo}

O município de Altamira está localizado na Amazônia Oriental, especificamente no oeste do estado do Pará, nas coordenadas geográficas $03^{\circ} 12^{\prime} 00^{\prime \prime} \mathrm{S}$ e $52^{\circ} 13^{\prime} 45^{\prime \prime} \mathrm{W}$ e situa-se na margem esquerda do rio Xingu, a 74 metros de altitude e distante cerca de $512 \mathrm{~km}$ de Belém capital do estado do Pará (MOURA \& RIBEIRO, 2009). Este município faz fronteira ao Norte com Vitória do Xingu, Brasil Novo, Medicilândia, Uruará, Placas e Rurópolis; à leste com Senador José Porfírio, São Félix do Xingu e Vitória do Xingu; ao Sul com o Estado do Mato Grosso; e à oeste com Itaituba, Trairão e Novo Progresso (IDESP, 2014) (Figura 1).

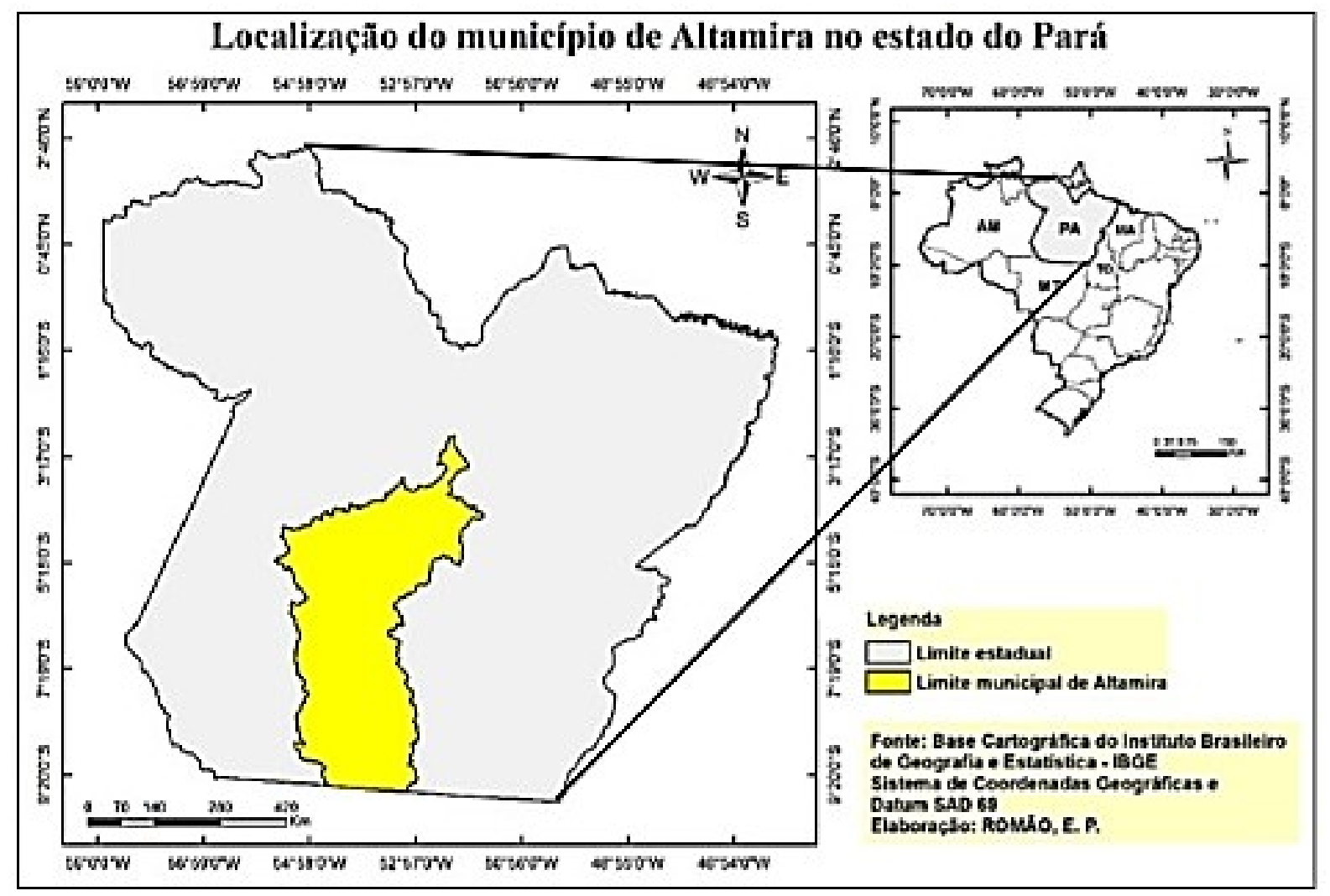

FIGURA 1: Localização do município de Altamira no Estado do Pará.

Fonte: Autores (2015). 
Altamira surgiu por meio de missões jesuítas em meados do século XVII, mas apenas em 1917, o distrito de Altamira foi elevado à categoria de município. Atualmente, com uma extensão territorial de $159.533,255 \mathrm{~km}^{2}$ corresponde ao maior município do mundo, apresentando no senso de 2010 uma população de 99.075 habitantes e com estimativa de 108.382 habitantes em 2015, o que representa uma densidade demográfica de $0,62 \mathrm{hab} . / \mathrm{km}^{2}$, segundo dados do IBGE Cidades (IBGE, 2015).

O município está inserido no Bioma Amazônico, apresentando uma extensa área territorial coberta pela floresta equatorial densa com árvores de grande porte e vegetação emergente. Sua fauna acompanha a variedade biológica da flora, apresentando-se rica e diversificada (ALTAMIRA, 2012). Além da floresta amazônica, o município apresenta outras fisionomias como a vegetação secundária e culturas como cana-de-açúcar, de cacau, além de cultivos de subsistência. $\mathrm{O}$ principal rio do município é o Xingu, com $1.400 \mathrm{~km}$ de extensão, mas exibe também uma variedade de acidentes geográficos, como: igarapés, ilhotas, praias de água doce, serras, cachoeiras e furos (IDESP, 2014).

\section{Procedimentos Metodológicos}

Para delimitação da área territorial do município de Altamira foi utilizado o formato de arquivo digital shapefile obtido através da base cartográfica digital do Instituto Brasileiro de Geografia e Estatística, na escala 1:250.000 (IBGE, 2015). A análise deste estudo foi baseada nos dados do projeto TerraClass, referentes ao mapeamento dos anos de 2008 e 2012. Os dados digitais deste projeto são de imagens do satélite Landsat 5 (sensor TM) com coordenadas geográficas no sistema Lat/Long e conexão de dados através do SAD 69 (INPE, 2015). Para o município de Altamira foram utilizadas cenas das seguintes órbitas-ponto: 225-62, 225-63, 22564, 225-65, 225-66, 225-67, 226-62, 226-63, 226-64, 226-65, 226-66, 226-67, $227-$ $63,227-64,227-65$ e 227-66.

A metodologia aplicada para o mapeamento do uso e cobertura da terra, foi desenvolvida pelo projeto TerraClass, abrangendo 12 classes temáticas: Agricultura anual, Área não observada, Área urbana, Mineração, Mosaico de ocupações, Outros, Pasto com solo exposto, Pasto limpo, Pasto sujo, Regeneração com pasto, Reflorestamento e Vegetação secundária, além das classes temáticas importadas do banco de dados do projeto PRODES, que são: Floresta, Não floresta, Desmatamento e Hidrografia (INPE \& EMBRAPA, 2013), encontrando-se descritas no Quadro 1.

QUADRO 1 - Classes temáticas utilizadas pelo Projeto TerraClass e suas respectivas descrições

\begin{tabular}{|l|l|}
\hline \multicolumn{1}{|c|}{ CLASSE } & \multicolumn{1}{c|}{ DESCRIÇÃO } \\
\hline Desflorestamento & $\begin{array}{l}\text { Classe mapeada pelo PRODES (Desflorestamento } \\
\text { anual). }\end{array}$ \\
\hline Floresta & $\begin{array}{l}\text { Classe mapeada pelo PRODES (Vegetação arbórea } \\
\text { pouco alterada ou sem alteração, com formação de } \\
\text { dossel contínuo. }\end{array}$ \\
\hline Hidrografia & $\begin{array}{l}\text { Classe mapeada pelo PRODES (Águas superficiais } \\
\text { formadoras de espelhos d'água. }\end{array}$ \\
\hline Não floresta & $\begin{array}{l}\text { Classe mapeada pelo PRODES (Formação vegetal } \\
\text { natural não florestal com características de cerrado, }\end{array}$ \\
\hline
\end{tabular}




\begin{tabular}{|c|c|}
\hline & campinas ou campinaranas). \\
\hline Agricultura anual & $\begin{array}{l}\text { Áreas extensas com predomínio de culturas de ciclo } \\
\text { anual, sobretudo de grãos, com padrão tecnológico } \\
\text { elevado. }\end{array}$ \\
\hline Área não observada & $\begin{array}{l}\text { Áreas que tiveram sua interpretação impossibilitada pela } \\
\text { presença de nuvens ou sombra de nuvens. }\end{array}$ \\
\hline Área urbana & $\begin{array}{l}\text { Manchas urbanas decorrentes da concentração } \\
\text { populacional formadora de lugarejos, vilas ou cidades. }\end{array}$ \\
\hline Mineração & $\begin{array}{l}\text { Áreas de extração mineral com a presença de clareiras e } \\
\text { solos expostos, envolvendo desflorestamento nas } \\
\text { proximidades de águas superficiais. }\end{array}$ \\
\hline $\begin{array}{l}\text { Mosaico de } \\
\text { ocupações }\end{array}$ & $\begin{array}{l}\text { Áreas representadas por uma associação de diversas } \\
\text { modalidades de uso da terra e que devido a resolução } \\
\text { espacial das imagens de satélite não é possível uma } \\
\text { descriminação entre seus componentes. }\end{array}$ \\
\hline Outros & $\begin{array}{l}\text { São áreas que não se enquadravam nas chaves de } \\
\text { classificação e apresentavam um padrão de cobertura } \\
\text { diferenciada de todas as classes do projeto. }\end{array}$ \\
\hline $\begin{array}{l}\text { Pasto com solo } \\
\text { exposto }\end{array}$ & $\begin{array}{l}\text { Áreas que, após o corte raso da floresta e o } \\
\text { desenvolvimento de alguma atividade agropastoril, } \\
\text { apresentam uma cobertura de pelo menos } 50 \% \text { de solo } \\
\text { exposto. }\end{array}$ \\
\hline Pasto limpo & $\begin{array}{l}\text { Áreas de pastagem em processo produtivo com } \\
\text { predomínio de vegetação herbácea e cobertura de } \\
\text { gramíneas entre } 90 \% \text { e } 100 \% \text {. }\end{array}$ \\
\hline Pasto sujo & $\begin{array}{l}\text { Áreas de pastagem em processo produtivo com } \\
\text { predomínio vegetação herbácea e cobertura de } \\
\text { gramíneas entre } 50 \% \text { e } 80 \% \text {, associado à presença de } \\
\text { vegetação arbustiva esparsa com cobertura entre } 20 \% \text { e } \\
50 \% \text {. }\end{array}$ \\
\hline Reflorestamento & $\begin{array}{l}\text { Áreas caraterizadas pelo plantio homogêneo de } \\
\text { espécies arbóreas. Apresentam como característica o } \\
\text { plantio em grandes talhões de formato geométrico } \\
\text { regular. }\end{array}$ \\
\hline $\begin{array}{l}\text { Regeneração com } \\
\text { pasto }\end{array}$ & $\begin{array}{l}\text { Áreas que, após o corte raso da vegetação natural e o } \\
\text { desenvolvimento de atividade agropastoril, encontram-se } \\
\text { no início do processo de regeneração da vegetação } \\
\text { nativa, apesentando espécies arbustivas e pioneiras } \\
\text { arbóreas. }\end{array}$ \\
\hline Vegetação secundária & $\begin{array}{l}\text { Áreas que, após a supressão total da vegetação } \\
\text { florestal, encontram-se em processo avançado de } \\
\text { regeneração da vegetação arbustivas e/ou arbóreas. }\end{array}$ \\
\hline
\end{tabular}

Fonte: Inpe \& Embrapa (2013).

Os procedimentos realizados foram: A) aquisição do shapefile vetorial do IBGE; B) aquisição das cenas do projeto TerraClass para os anos de 2008 e 2012; C) processamento dos dados no software Spring versão 5.2.6, tais como: a união dos arquivos, análise topológica dos dados, a conversão dos vetores para o formato raster, a união das classes temáticas e a conversão de áreas das classes temáticas em km²; D) Elaboração do design final dos mapas no software TerraAmazon 4.5.1. 


\section{RESULTADOS E DISCUSSÃO}

As análises realizadas mostram alterações no uso e cobertura do solo no município de Altamira-PA nos anos de 2008 e 2012, destacando-se aumento nas seguintes classes temáticas: Área urbana, Mineração, Pasto sujo, Pasto limpo, Regeneração com pasto e Vegetação secundária, entretanto, as classes Hidrologia e Não Floresta mantiveram-se iguais em ambos anos de análise, as demais classes tiveram diminuição (Tabela 1).

O aumento da área urbana, que correspondia a uma cobertura de $10,66 \mathrm{~km}^{2}$ em 2008 passou para 35,86 km² em 2012, representando um aumento na cobertura urbana de $25,2 \mathrm{~km}^{2}$ em apenas cinco anos (Tabela 1). Tal resultado deve-se principalmente ao fato de estar em andamento, neste período, no município de Altamira, a implantação do empreendimento Belo Monte para a construção da usina hidrelétrica de mesmo nome. Este empreendimento está atraindo muitas pessoas para trabalhar em seus canteiros-de-obras. O acréscimo de pessoas no município, ocasiona a expansão do número de moradias, para abrigar os imigrantes que são provenientes de diferentes regiões. Esse tipo de crescimento populacional é comum em obras de tal magnitude realizadas no Brasil e, por tal razão, ressalta-se que projetos desenvolvimentistas favorecem o surgimento de núcleos urbanos e até mesmos de muitas cidades, gerando transformações na paisagem (CARDOSO \& NEGRÃO, 2012).

TABELA 1 - Área em $\mathrm{km}^{2}$ e participação relativas das classes de uso e ocupação do município de Altamira-PA, com base no mapeamento do projeto TerraClass durante os anos de 2008 e 2012.

\begin{tabular}{crrrr}
\hline Classe/Ano & $\mathbf{2 0 0 8} \mathbf{( k m}^{\mathbf{2}} \mathbf{\%}$ & $\mathbf{\%}$ & $\mathbf{2 0 1 2} \mathbf{( k m}^{\mathbf{2}} \mathbf{~}$ & $\mathbf{\%}$ \\
\hline Agricultura anual & 0,01 & 0,00 & 0,00 & 0,00 \\
Mosaico de ocupações & 9,66 & 0,01 & 39,52 & 0,02 \\
Área não observada & $1.227,30$ & 0,77 & 879,91 & 0,55 \\
Área urbana & 10,66 & 0,01 & 35,86 & 0,02 \\
Desflorestamento & 335,33 & 0,21 & 228,46 & 0,14 \\
Floresta & $147.941,33$ & 92,74 & $146.864,08$ & 92,06 \\
Hidrografia & $1.684,05$ & 1,06 & $1.684,06$ & 1,06 \\
Mineração & 18,02 & 0,01 & 25,91 & 0,02 \\
Não floresta & $3.796,94$ & 2,38 & $3.797,04$ & 2,38 \\
Outros & 2,11 & 0,00 & 26,07 & 0,02 \\
Pasto sujo & 692,56 & 0,43 & $1.080,90$ & 0,68 \\
Pasto limpo & $2.183,61$ & 1,37 & $2.728,78$ & 1,71 \\
Pasto com solo exposto & 0,89 & 0,00 & 0,00 & 0,00 \\
Regeneração com pasto & 559,90 & 0,35 & 667,87 & 0,42 \\
Reflorestamento & 0,00 & 0,00 & 0,14 & 0,00 \\
Vegetação secundária & $1.061,48$ & 0,67 & $1.463,57$ & 0,92 \\
\hline
\end{tabular}

Fonte: Autores (2015), baseado em dados do TerraClass 2008 e 2012.

A classe Mineração também apresentou um aumento na área do município, sendo de $18,02 \mathrm{~km}^{2}$ no ano de 2008, passando para 25,91 km² em 2012, correspondendo à um acréscimo dessa área de $7,89 \mathrm{~km}^{2}$ (Tabela 1). 0 acréscimo ENCICLOPÉDIA BIOSFERA, Centro Científico Conhecer - Goiânia, v.14 n.25; p.118 2017 
desta forma de uso pode ser explicado pelo crescimento de atividades mineradoras na região amazônica. Assim, nos últimos anos, várias iniciativas vêm sendo desenvolvidas, como a implantação da multinacional canadense Belo Sun Mining Corp., que se instalou em Altamira na área conhecida como a Volta do Grande Xingu, localizada aproximadamente a $14 \mathrm{Km}$ da Hidrelétrica Belo Monte. Tal empresa estima uma extração de ouro no montante de aproximadamente cinco toneladas por ano durante um período de 17 anos (BELO SUN MINING CORP., 2016).

As classes 'Pasto sujo' e 'Pasto limpo', estão associadas às pastagens, e também apresentaram aumento em suas áreas, a primeira despontou de $692,56 \mathrm{~km}^{2}$ em 2008, para $1080,90 \mathrm{~km}^{2}$ em 2012, representando uma ampliação na área de $388,34 \mathrm{~km}^{2}$. A segunda evidenciou um aumento de 545, $17 \mathrm{~km}^{2}$, visto que em 2008 apresentava área de 2.183, $61 \mathrm{~km}^{2}$ e em 2012 de 2.728,78 km² (Tabela 1). Ressaltase que a pecuária é uma atividade extensiva no município de Altamira, em especial, no entorno da Rodovia Transamazônica, onde foi planejada a implantação de projetos agrícolas, mas que, devido as condições de fertilidade do solo, algumas dessas atividades não foram inseridas, dando margem para a ampliação do rebanho bovino. Com a expansão, o consumo dos pastos foi acelerado, esgotando-os mais rapidamente, desencadeando o abando da área para pousio, tornando-se necessário a instalação de novas áreas para pastagens, conforme observado nos resultados apresentados. Entretanto, as implantações destas pastagens exigem maior área para o plantio e assim, a derrubada de florestas é sempre inevitável para atender a esta necessidade. Tal ação promove o aumento do desmatamento e impactos sobre o solo e a biodiversidade. Nesta ótica, é importante ressaltar que os processos de mudança da paisagem, como o desmatamento ocorre em um nível mais acelerado que o ciclo natural dos ecossistemas, na manutenção de sua biodiversidade (ADAMI et al., 2015).

Com relação a classe Floresta, embora nos anos de 2008 e 2012 o tamanho destas áreas em percentual não apresentasse uma grande diferença, mas ao se analisar comparativamente a extensão territorial de tais áreas em relação ao município, percebe-se que o percentual de 0,02\% (Tabela 1) corresponde há uma área de $1.077 \mathrm{~km}^{2}$, o que representa uma grande supressão da floresta nativa. Este declínio de áreas florestadas em Altamira, pode ser decorrente do aumento na área das classes associadas às pastagens, como Pasto Sujo e Pasto Limpo e de Mineração. Estes aumentos podem representar a expansão da pecuária extensiva (GERALDIN, 2015) e a expansão de projetos para exploração de ouro no município (BELO SUN MINING CORP., 2016), respectivamente.

A classe Regeneração com pasto também obteve acréscimo, passando de $559,90 \mathrm{~km}^{2}$ em 2008 para 667,87 km² em 2012, representando um aumento de $107,97 \mathrm{~km}^{2}$ dessa modalidade de uso da terra em Altamira. Ressalta-se que, se o processo de regeneração vegetacional destas áreas forem mantidos, poderão desenvolver-se a um nível de vegetação secundária. Entretanto, é importante mencionar que esta classe, apesar de encontrar-se em início de regeneração natural, representa uma pastagem com uso em abandono gradativo, indicando que haverá necessidade de utilização de novas áreas para pastagens e, assim sendo, compreendido como um indicador de desmatamentos futuros.

A classe de uso denominada Vegetação Secundária apresentou um visível aumento de 402,09 km², visto que em 2008 essa área correspondia a $1.061,48 \mathrm{~km}^{2}$ e em 2012 passou para 1.463,57 km². Assim, esta classe parece contrapor as demais formas de uso que desencadeiam o estímulo ao desmatamento, por 
representar as áreas em processo avançado de regeneração da vegetação, seja esta arbórea ou arbustiva. Este fato é comumente vivenciado na região amazônica, pelo abandono de áreas desmatadas, seja por inutilidade da área, improdutividade do solo ou até pelo deslocamento de atividades econômicas, agrícolas, pecuárias ou outras. Estes dados avaliados para o município de Altamira representam áreas não mais utilizadas, principalmente em torno da Rodovia Transamazônica, após um ciclo agropecuário. Entretanto, vale ressaltar que embora a vegetação secundária represente um importante estrato vegetal para o meio ambiente, os reflorestamentos com espécies vegetais nativas da área deveriam ser replantados pelos donos das mesmas, durante o processo sucessional da vegetação, para garantir a manutenção de espécies originais da região, dando uma caracterização mais próxima possível da vegetação nativa.

Contudo, vale ressaltar que na análise das imagens fornecidas pelo TerraClass referentes a classe 'Área não observada', correspondente as áreas impossibilitadas de serem observadas pelo sensor (devido a presença de nuvens), no ano de 2012 foi ampliada possibilitando maior visualização do município de Altamira e por isso, as imagens obtidas para este ano podem ser consideradas mais fidedignas que as de 2008. A classe 'Reflorestamento' somente foi incluída na classificação como uma forma de uso da terra no TerraClass a partir de 2012, razão pela qual essa categoria foi registrada apenas neste ano. Deve-se ressaltar que esta classe introduzida ao TerraClass, é importante para um melhor monitoramento da cobertura do solo e também para se verificar se as políticas de reflorestamento estão sendo implementadas através de seu monitoramento.

Portanto, os resultados apresentados e discutidos neste trabalho geraram mapas e recortes do município de Altamira, correspondentes as figuras 2 e 3 , que através de seus pixels verifica-se as alterações mencionadas neste estudo. Os mapas de classificação confirmam os resultados apresentados anteriormente, embora não bem visíveis devido a extensão territorial do município. Entretanto, no recorte da área ao norte do município, onde está situada a sede do mesmo, são perceptíveis a dinâmica e o aumento das áreas de classes do uso e ocupação do solo, que em grande parte apresentaram visíveis acréscimos, principalmente na expansão urbana. Também é aparente no mapa o aumento de classes nas regiões leste e sudoeste do município, principalmente a forma de uso pasto limpo, como revela a figura 3. 


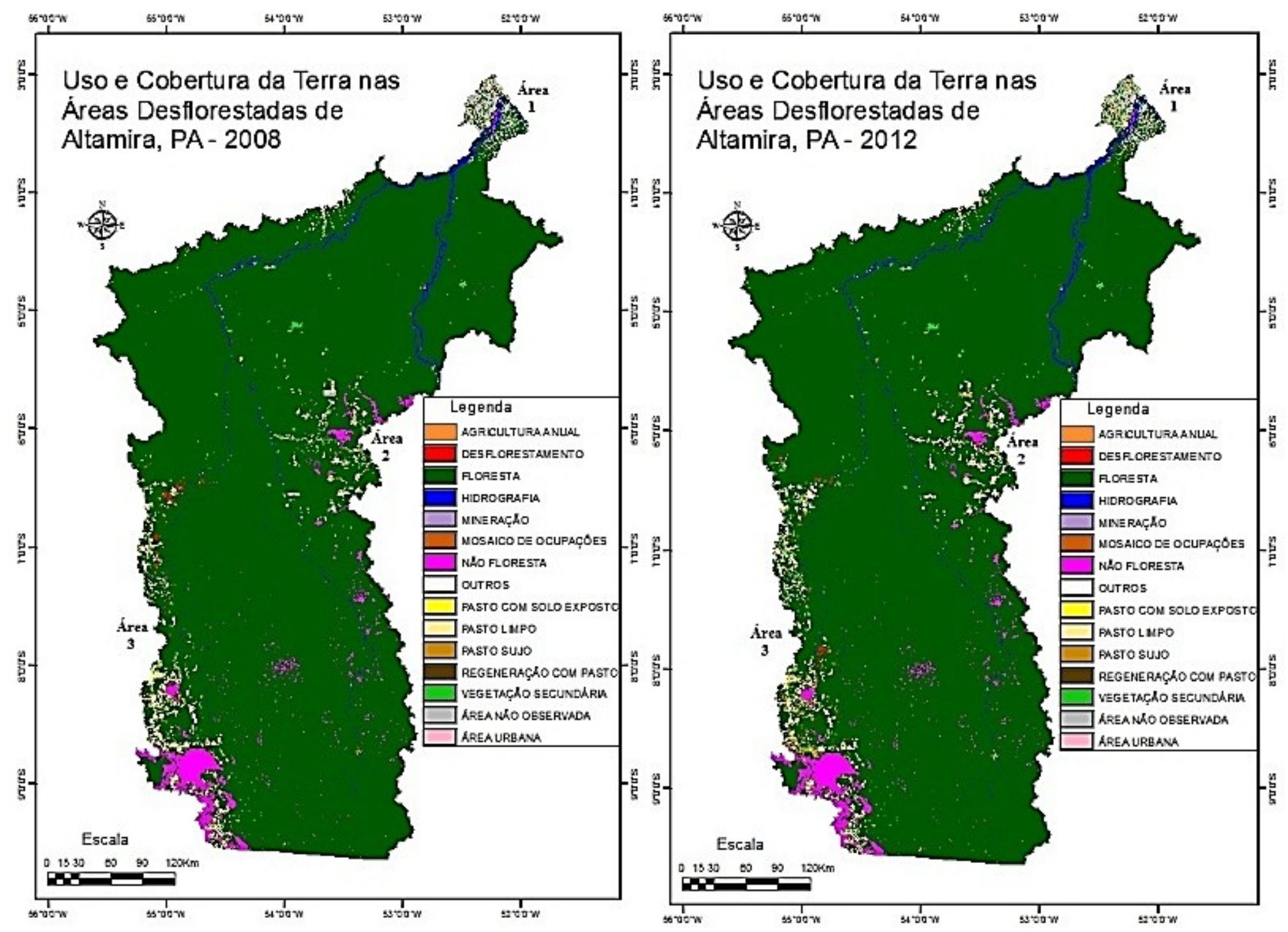

FIGURA 2. Uso e cobertura da terra nas áreas desflorestadas do município de Altamira-PA, no ano de 2008 e 2012 , com suas áreas de recorte denominadas Área 1, Área 2 e Área 3. Fonte: Autores (2015), baseado em dados do TerraClass 200822012. 

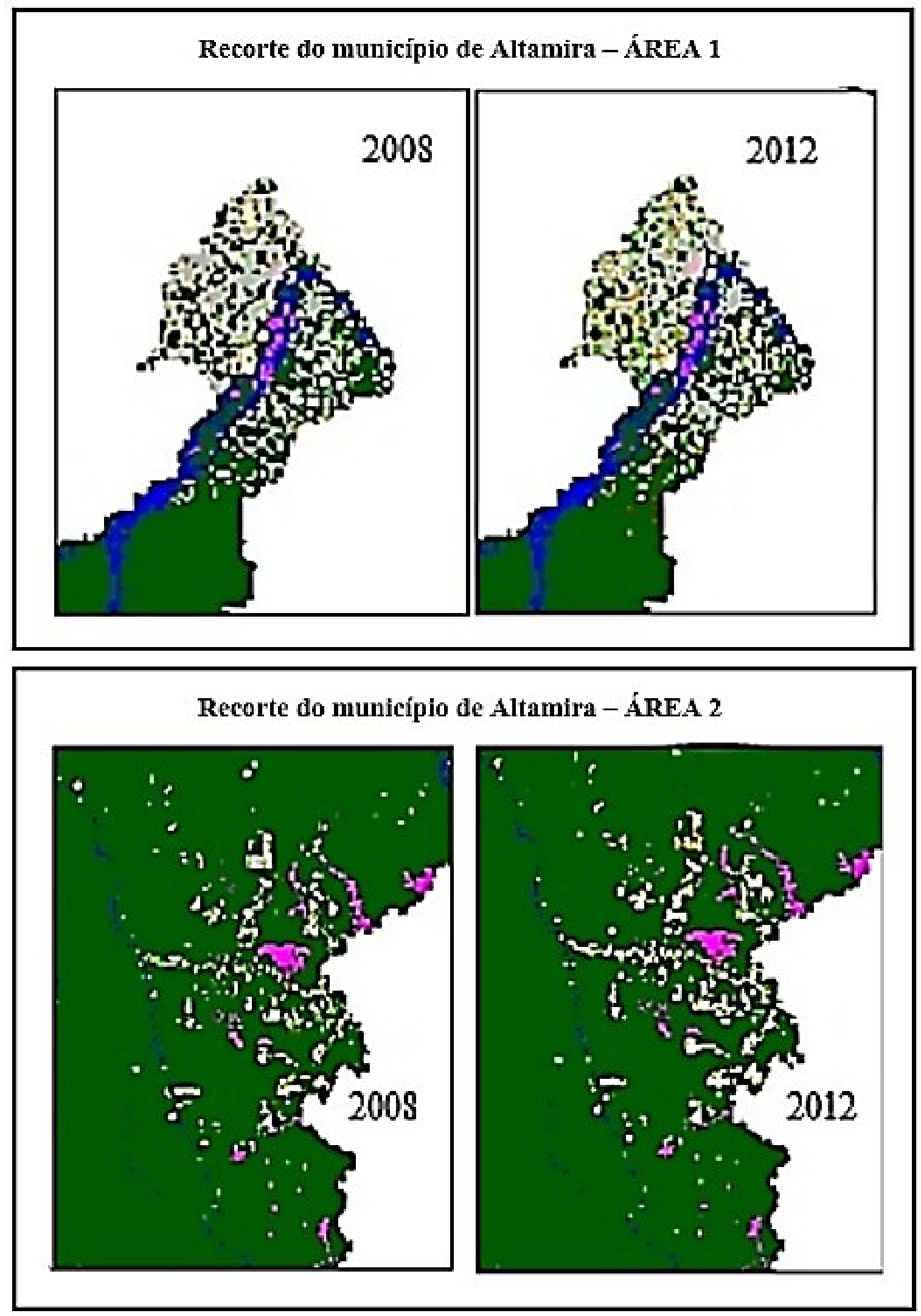


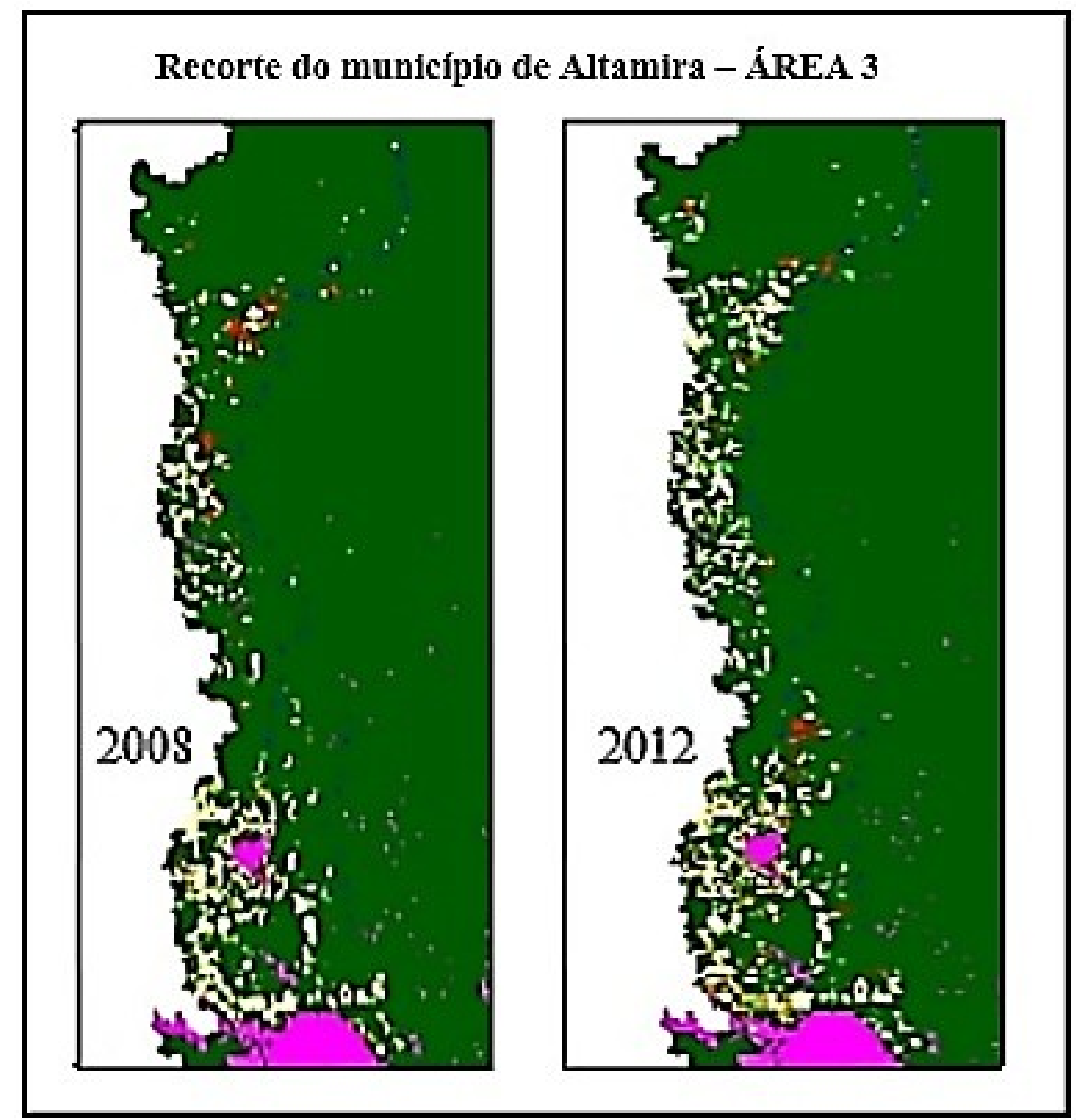

FIGURA 3: Aspecto do recorte da Área 1, Área 2 e Área 3 do município de Altamira, nos anos de 2008 e 2012. Fonte: Autores (2015), baseado em dados do TerraClass 2008 e 2012.

\section{CONCLUSÃO}

Este estudo revela um aumento considerável de maior parte das classes de uso e cobertura da terra a partir dos dados do projeto TerraClass, analisados para o município de Altamira-PA, nos anos de 2008 e 2012. Poucas formas de uso não condizem com este quadro, como as classes Agricultura e Pasto com solo exposto, por não apresentaram crescimento expressivos nos períodos analisados. É importante ressaltar que a classe Floresta, principal representação da vegetação nativa arbórea, também apresentou uma pequena redução, entretanto, este aparente declínio corresponde à uma extensa área em $\mathrm{km}^{2}$ de floresta desmatada no município, ocasionando impactos sobre a biodiversidade local e regional, necessitando assim de uma atenção direcionada para esta formação vegetal.

A classe Vegetação Secundária revelou-se crescente em Altamira, sendo considerada importante sobre o ponto de vista ambiental, pois corresponde ao processo de regeneração vegetacional que é eficaz no sequestro de CO2 da ENCICLOPÉDIA BIOSFERA, Centro Científico Conhecer - Goiânia, v.14 n.25; p.123 
atmosfera. De modo contrário, o aumento da classe 'Pasto Limpo' é preocupante, visto que não contribui com o sequestro de carbono e sua implantação requer desflorestamento, além disso, está comumente associado à criação de bovinos, os quais contribuem com emissão de gás metano à atmosfera.

Em suma, confirmamos a existência de uma dinâmica no uso e cobertura da terra no município de Altamira para os anos analisados, entretanto, estudos adicionais que considerem a redução da escala e a temporalidade do monitoramento, se fazem necessários. Destaca-se que pesquisas desta natureza são importantes para gerar informações que venham promover ações de redução do desmatamento de florestas nativas e a manutenção da vegetação secundária, contribuindo com a consolidação de políticas públicas. Dessa forma, colaboram para a manutenção e recuperação da biodiversidade e de alguns serviços ecológicos, além de incentivar junto a sociedade, a conscientização do uso adequado da terra.

\section{REFERÊNCIAS}

ADAMI, M.; GOMES, A. R.; COUTINHO, A. C.; ESQUERDO, J. C. D. M.; ALMEIDA, C.A.; Valeriano, D.M.; Escada, M.I.S.; Rennó, C.D. Estimativa de área de vegetação secundária na Amazônia Legal Brasileira. Acta Amazonica, v.40, n.2, p.289-302, 2010.

ALTAMIRA / Secretaria Municipal de Gestão do Meio Ambiente e Turismo. Inventário da Oferta Turística de Altamira (PA). SEMAT, 523 p., 2012.

BECKER, B. K. Amazônia. 5 ed. São Paulo: Editora Ática, p. 44-53, 1995.

Amazônia. São Paulo: Editora Ática, 1998.

BELO SUN MINING CORP. Avançando Rapidamente Nosso Projeto Ouro Volta Grande, Brasil. 2016. Disponível em: <http://www.belosun.com/> Acesso em: 11/05/2016.

CARDOSO, A. C. D.; NEGRÃO, M. R. G.; Das máquinas autoritárias de planejamento do século $X X$, às máquinas de crescimento urbano do século $X X I$ : 0 caso do sudeste do Pará. XV Encontro da associação nacional de Programas de Pós-graduação e Pesquisa em Planejamento urbano e regional, 2013, Recife. 2012.

CASTRO, E. Políticas de ordenamento territorial, desmatamento na Amazônia. Novos Cadernos do NAEA, Belém, v. 10, n. 52, p. 105-126, 2007.

CORDOVIL, J.C.S.; CEBULISKI, B.S.P.; COSTA, W.L.; NUNES, P.B. Políticas públicas, atividade turística e estratégias de desenvolvimento: uma abordagem sobre o turismo em Altamira (PA). Revista Brasileira de Ecoturismo. São Paulo, v.6, n.5, pp.850- 861, nov-2013/jan-2014.

COUTINHO, A. C. Condicionantes da expansão da fronteira agrícola em Mato Grosso. Revista de Política agrícola. Brasília, DF. Secretaria Nacional de Política Agrícola, n. 1, p. 80-97, 2009. 
FEARNSIDE, P. M. Desmatamento na Amazônia Legal: história, índices e consequências. Megadiversidade. Belo Horizonte, v. 1, n. 1, p. 113-123, 2005.

Hidrelétricas na Amazônia: impactos ambientais e sociais na tomada de decisões sobre grandes obras. - Manaus: Editora do INPA, 2015.

FOLEY, J. A.; DEFRIES, R.; ASNER, G. P.; BARFORD, C.; BONAN, G.; CARPENTER, S. R.; [et al.]. Global consequences of land use. Science, v. 309, p. 570-574, 2005.

GERALDIN, R. M. Entre trânsitos e consumos: a presença dos trabalhadores de Belo Monte em Altamira, PA. 2015. 130f. Dissertação (Mestrado em Antropologia Social). Universidade de Brasília. Brasília. 2015.

HANSEN, M. C.; POTAPOV, P. V.; MOORE, R.; HANCHER, M.; TURUBANOVA, S. A.; TYUKAVINA, A.; [et al.]. High-Resolution Global Maps of 21st-Century Forest Cover Change. Science, v. 342, n. 6160, p. 850-853, 2013.

HERRERA, J. A.; MOREIRA, R. P.; Resistência e Conflitos Sociais na Amazônia Paraense: a luta contra o empreendimento Hidrelétrico de Belo Monte. CampoTerritório: revista de geografia agrária, v. 8, n. 16, p. 130-151, ago., 2013.

IANNI, O. Colonização e Contra-Reforma Agrária na Amazônia. Petrópolis: Editora Vozes, 137 p., 1979.

IBGE - Instituto Brasileiro de Geografia e Estatística. Censo 2010. Brasília: Ministério do Planejamento, Orçamento e Gestão, 2011.

IBGE Cidades @. Disponível em: http://www.cidades.ibge.gov.br/xtras/uf.php?lang=\&coduf=15\&search=para. Acesso em: 02 dez. 2015.

IDESP - Instituto de Desenvolvimento Econômico, Social e Ambiental do Pará. Estatística Municipal - Altamira, PA. Belém, 2014.

INPE \& EMBRAPA. Uso e cobertura da terra nas áreas desflorestadas da Amazônia Legal: TerraClass 2008. (Org.) Alexandre Camargo Coutinho; Cláudio Almeida; Adriano Venturieri; Júlio César Dalla Mora Esquerdo; Maurício Silva. Brasília, DF: Embrapa; Belém: INPE 2013.

INPE, Instituto Nacional de Pesquisas Espaciais. Programa de Monitoramento do Desflorestamento das Formações Vegetais da Amazônia Legal. Disponível em http://www.obt.inpe.br/prodes/prodes_1988_2013.htm. Acesso em 12 de junho de 2015. São José dos Campos. 2015.

Programa de Cálculo do Desflorestamento da Amazônia (PRODES): desflorestamento nos municípios da Amazônia Legal. Ano base 2011. Disponível em: <http://www.dpi.inpe.br/prodesdigital/prodesmunicipal.php>. São José dos Campos. 2011.

LAURANCE, W. F.; FERREIRA, L. V.; RANKIN-de-MERONA, J.; LAURANCE, S. G.; HUTCHINGS, R. W.; LOVEJOY, T. E. Effects of Forest Fragmentation on 
Recruitment Patterns in Amazonian Tree Communities. Conservation Biology 12(2): 460-464. 2008.

MAHAR, D. J. Government Polices and Deforestation in Brazil's Amazon Region. Washington, Word Bank Publication. 1989.

MEIRELLES FILHO, João Carlos de Souza. É possível superar a herança da ditadura brasileira (1964-1985) e controlar o desmatamento na Amazônia? Não, enquanto a pecuária bovina prosseguir como principal vetor de desmatamento. Boletim do Museu Paraense Emílio Goeldi. Ciências Humanas, v. 9, n. 1, p. 219241, jan.-abr. 2014.

MORAIS, R. P.; CARVALHO, T. M. de; Cobertura da Terra e Parâmetros da Paisagem no município de Caracaraí-Roraima. Revista Geográfica Acadêmica. v. 7, n. 1 (xii. 2013). 2013.

MOURA, A. R.; RIBEIRO, J. C. Altamira no contexto geográfico. Belém, PA: Ed. do Autor. 119p., 2009.

UMBUZEIRO, A.U.B. Altamira e sua história. 4 ed. Belém: Ponto Press, 2012.

VIEIRA, I. C.; SILVA, J. M. C. TOLEDO, P. M.; Estratégias para evitar a perda de biodiversidade na Amazônia. Estudos Avançados. 19 (54). 2005. 